\title{
Evaluation of Salmon Adhesion on PET-Metal Interface by ATR, FT-IR, and Raman Spectroscopy
}

\author{
E. Zumelzu, ${ }^{1}$ M. J. Wehrhahn, ${ }^{1}$ F. Rull, ${ }^{2}$ H. Pesenti, ${ }^{1}$ O. Muñoz, ${ }^{1}$ and R. Ugarte ${ }^{1}$ \\ ${ }^{1}$ Institute of Materials, Chemistry and Food Science, University Austral of Chile, P.O. Box 567, 5111187 Valdivia, Chile \\ ${ }^{2}$ Department of Condensed Matter Physics, University of Valladolid, 47002 Valladolid, Spain \\ Correspondence should be addressed to E. Zumelzu; ezumelzu@uach.cl
}

Received 8 August 2014; Accepted 1 December 2014

Academic Editor: Ming-Guo Ma

Copyright (c) 2015 E. Zumelzu et al. This is an open access article distributed under the Creative Commons Attribution License, which permits unrestricted use, distribution, and reproduction in any medium, provided the original work is properly cited.

\begin{abstract}
The material employed in this study is an ecoefficient, environmentally friendly, chromium (VI)-free (noncarcinogenic) metal polymer. The originality of the research lies in the study of the effect of new production procedures of salmon on metal packaging with multilayer polyethylene terephthalate (PET) polymer coatings. Our hypothesis states that the adhesion of postmortem salmon muscles to the PET polymer coating produces surface and structural changes that affect the functionality and limit the useful life of metal containers, compromising therefore their recycling capacity as ecomaterials. This work is focused on studying the effects of the biochemical changes of postmortem salmon on the PET coating and how muscle degradation favors adhesion to the container. The experimental design considered a series of laboratory tests of containers simulating the conditions of canned salmon, chemical and physical tests of food-contact canning to evaluate the adhesion, and characterization of changes in the multilayer PET polymer by electron microscopy, ATR, FT-IR, and Raman spectroscopy analyses. The analyses determined the effect of heat treatment of containers on the loss of freshness of canned fish and the increased adhesion to the container wall, and the limited capability of the urea treatment to remove salmon muscle from the container for recycling purposes.
\end{abstract}

\section{Introduction}

There is currently a dispute regarding biosafety in the salmon farming industry due to the loss of freshness of canned fish, as evidenced by changes in $\mathrm{pH}$ and $\mathrm{K}$ index value, and the adhesion of small muscle portions to the protective polymer coating of the container walls. Spoilage has eventually an impact on polymer coatings regarding their ecomaterial capabilities for recycling due to the surface changes undergone by the polymer [1-5].

This work evaluated the effect of the salmon farming processes on the performance of metal-polymer composites coated with low-permeability, homogeneous polymers employed in salmon canning.

The release of ammonia compounds, hydrogen sulfide, and mercaptans (indole, skatole, and other sulfur-containing chemical compounds) is indicative of the microbiological spoilage of fish and depends on the storage temperature [6$10]$.
Such release generally tends to produce chemical changes on the industrial molecules and is strongly related to the crystallinity of polymers; thus, polyethylene terephthalate (PET) polymer coatings may degrade under extreme conditions [1114].

This study addresses the impact of the new aquaculture production practices on polyethylene terephthalate (PET) coatings protecting electrolytic chromium coated steel (ECCS) plates, employed as canning materials, resulting from the biochemical changes undergone by the postmortem salmon and its adherence to the can walls; therefore, it is essential to determine the freshness degree of canned salmon fish and its influence as a factor of adhesion.

These are fundamental topics focused on the basic understanding of the mechanics and physics of structural and functional materials at different length scales to accurately determine their properties in relation to the underlying multimaterial microstructures. 
To ensure sufficient shelf life, canned food is heat-treated by steam, steam-air mixtures, water, or spraying water. The coldest spot in the can is used as the reference point to determine whether the cans have received an adequate heat treatment. The heat treatment should ensure the inactivation of microorganisms that cause food poisoning and spoilage. The amount of heating needed in the coldest spot of the packaged food is in the range $4-12 \mathrm{~min}$ at $121^{\circ} \mathrm{C}$ for some typical canned food products $[11,15,16]$. As a consequence of this heat treatment, some packed food products can partly adhere to the can wall.

An important aspect to consider is the production of energy in the postmortem muscle, where the oxygen supply to the muscle tissue is interrupted and then the energy production is restricted. The glycogen (storage carbohydrate) or fats are oxidized in a series of reactions which finally produce carbon dioxide $\left(\mathrm{CO}_{2}\right)$, water, and adenosine triphosphate (ATP). This type of respiration occurs in two stages: anaerobic and aerobic. The latter depends on the continuous presence of oxygen $\left(\mathrm{O}_{2}\right)$, only available in the circulatory system [17]. Postmortem glycolysis results in the accumulation of lactic acid with the concomitant decrease in muscular $\mathrm{pH}$.

Bistac et al. [18] found several factors that affect mackerel adhesion to lacquered can walls. The reported effects clearly indicate that proteins are the major cause of this adhesion. Proteins consist of chains of covalently bound amino acids. Four types of bonds can be formed between the amino acids residues: covalent, electrostatic, hydrogen, and hydrophobic bonds [19]. These bonds are responsible for the structure of the native protein. During the heat processes, these interactions, especially the noncovalent bonds, are partly broken and hence they become available for interaction with, for instance, the surface of a can wall.

This study is focused on an integral view of the problems and considers recent new researches to integrate every necessary aspect for the optimization of multilayer materials used in salmon containers, which are subject to changes due to the canning processes employed to improve their commercialization, enhance sustainable recycling, and reduce energy consumption [20].

\section{Methodology}

The standard manufacturing protocol was employed to determine the salmon adhesion to the PET coating of the container and the morphological and chemical changes in the multilayers. Food cans were manufactured employing $50 \mathrm{~mL}$ of $2.5 \% \mathrm{NaCl}$ solution, sterilized at $120^{\circ} \mathrm{C}$ for 60 minutes, immersed in warm water bath ranging from $50^{\circ} \mathrm{C}$ to $80^{\circ} \mathrm{C}$ prior to sterilization, and stored for one week at $20^{\circ} \mathrm{C}$ before opening. The adhesion of salmon was determined by subtracting the weight of the can after cleaning with detergent and water from the weight of the can with portions of flesh attached to the polymer after emptying the container. The protein denaturation step or removal of muscle material from the PET surface was performed by soaking the emptied cans in $6 \mathrm{M}$ urea solution, since urea is well known for its capacity to form hydrogen bonds and is therefore used to unfold proteins.
A number of parameters typical of the analysis of fish spoilage were considered to estimate the freshness of canned salmon. These parameters were referred to as $K$ value and $\mathrm{pH}$.

The $K$ value is an important index for assessing the freshness quality of postmortem salmon. Nucleotide degradation analysis can be used to determine the degree of fish freshness before spoilage commences. This value can be obtained by calculating the concentration of nucleotides, inosine and hypoxanthine, in the muscle. Homogenized samples of salmon muscle were prepared with trichloroacetic acid. The homogenized sample was centrifuged and the supernatant was neutralized with $1 \mathrm{M}$ potassium hydroxide. Later, the $K$ value was determined by high-performance liquid chromatography (HPCL); the nucleotide concentration in the samples was assessed using a C8 reversed-phase column with phosphate buffer at $\mathrm{pH} 3.0$ as the mobile phase. The flow was maintained at $1 \mathrm{~mL} / \mathrm{min}$ and measured at a wavelength of $254 \mathrm{~nm}$.

The variations in the acidity of the solution resulting from the loss of freshness of canned salmon were measured in situ by the Unisense $\mathrm{pH}$ microelectrode.

The morphology of the composite's constituting layers was characterized by SEM to assess the level of degradation, intending to determine the relationships between surface structure and adhesion of salmon to the PET.

The changes in the multilayers were characterized by vibrational spectroscopy: ATR, FT-IR, and Raman. These techniques have proven extremely reliable and useful in the chemical fingerprinting of a wide range of materials employed in several applications [21-24]. The Raman analyses considered the employment of two back-illuminated fiber-coupled spectrometers featuring $633 \mathrm{~nm}$ and $785 \mathrm{~nm}$ wavelengths. The experiment considered mainly the data gathered with the $785 \mathrm{~nm}$ spectrometer. This device consisted of a multimode fiber laser BWTEK BRM-OEM-785 (785 nm), a Raman head BWTEK BAC100-785E, and an objective lens Zeiss Epiplan 50X/0.50 infinite/0 442850 (focal length). The maximum output of the laser through this lens was approximately $165 \mathrm{~mW}$; the laser spot diameter measured on the samples was 48 microns. The spectrometer employed was a BWTEK Prime T BTC661E-785CUST, covering a spectral range $0-3000 \mathrm{~cm}^{-1}$, with a spectral resolution of $5 \mathrm{~cm}^{-1}$, and the detection was performed by a CCD Hamamatsu S10141-1107S operating at $-10^{\circ} \mathrm{C}$. Several analyses were made to determine the chemical and orientation changes of the molecular chains and/or atomic rearrangements; in addition, atomic absorption measurements in the PET polymer were also performed.

\section{Results and Discussion}

3.1. Evaluation and Characterization of the Loss of Salmon Freshness and Adhesion to the PET Surface. Variations in canned salmon $\mathrm{pH}$ affect the PET surface and adhesion to the container wall in time. Figure 1 shows the $\mathrm{pH}$ gradient measurements of preserved salmon using Unisense $\mathrm{pH}$ microelectrode.

The in situ measurements reflected the acidity of the solution in the food container with changes from the head 


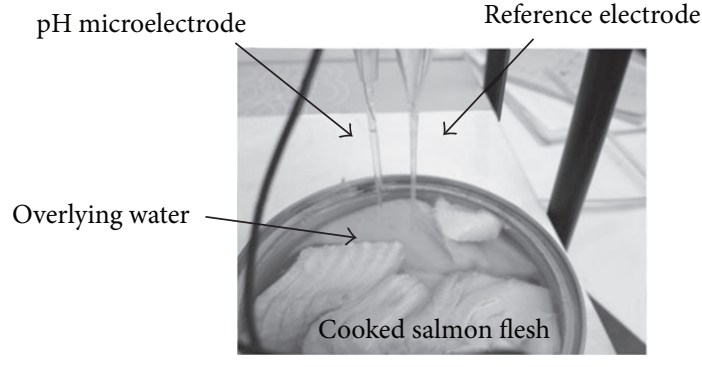

(a)

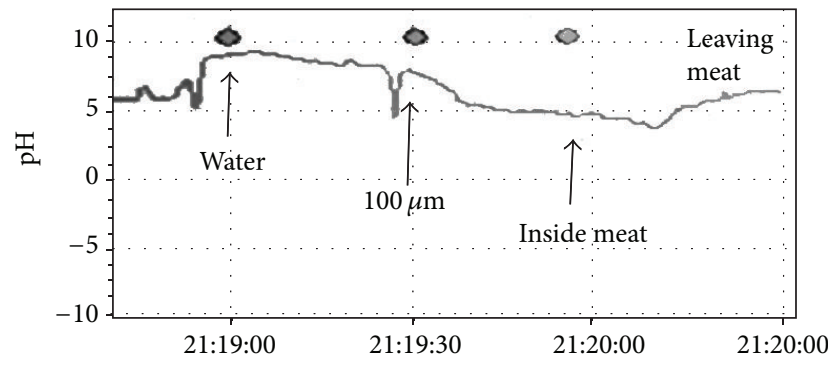

(b)

FIgURE 1: (a) Unisense pH microelectrode measurements performed in canned salmon samples; (b) there was a $\mathrm{pH}$ gradient from water overlying fluid towards the surface of the salmon meat. The gradient started at neutral $\mathrm{pH}$ 6-7 and ended at 4-5 inside the flesh.

space of the container to the bottom thereof, with evident variations from neutral to acid in areas of adhesion and around the PET polymer surface.

The following results were obtained after emptying the container, when determining adhesion of salmon to polymercoated can walls: a slight increase in the percentage of salmon muscle adhering to the PET-coated can wall was observed with longer storage times. The percentage of adhesion for the samples analyzed was in the range $2.5-4 \%$. The batch of cans stored for a period of 11 months showed the greatest adhesion. Possibly, this adhesion may have been enhanced by higher canning or storage temperatures. The lowest amount of adhesion was observed in cans opened after 4 months of storage. These results indicate that the major cause of salmon adhesion was mainly related to physical flaws on the PET surface, such as bends and micropores, as evidenced by electron microscopy observations. These surface defects may have favored a major role of the chemical interactions between the polymer coating and the proteins of salmon (Figure 2).

The following interaction has been suggested for the adhesion of proteins to PET: the carbonyl group in the ester bond of the PET coating is engaged to form hydrogen links with the amino group of the protein, which would explain the adhesion of salmon to the food container (Figure 3).

According to Fletcher et al., the $K$ value ranges from approximately $36 \%$ for fresh salmon to $73 \%$ for spoiled raw material. The results obtained indicated that canned salmon samples were within acceptable levels (Figure 4); however, those values were close to the maximum limit where loss of freshness occurs.

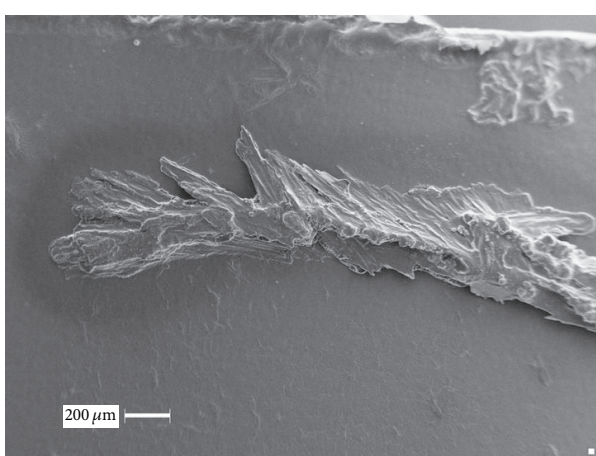

(a)

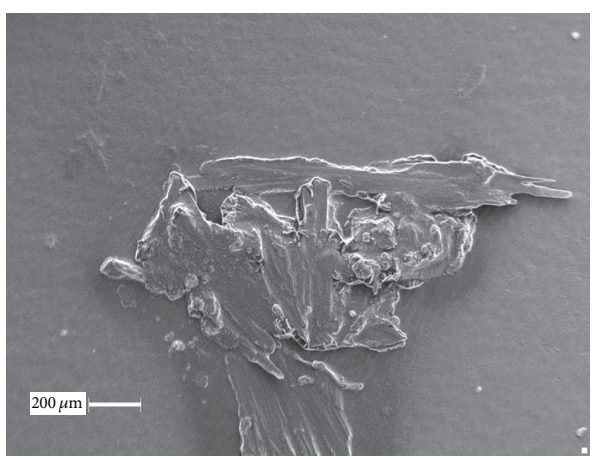

(b)

FIgURE 2: (a) The filiform and bifurcated muscle edges increase physical adhesion to the PET polymer coating; (b) salmon flesh not removed by the urea treatment and adhered to the container wall surface.

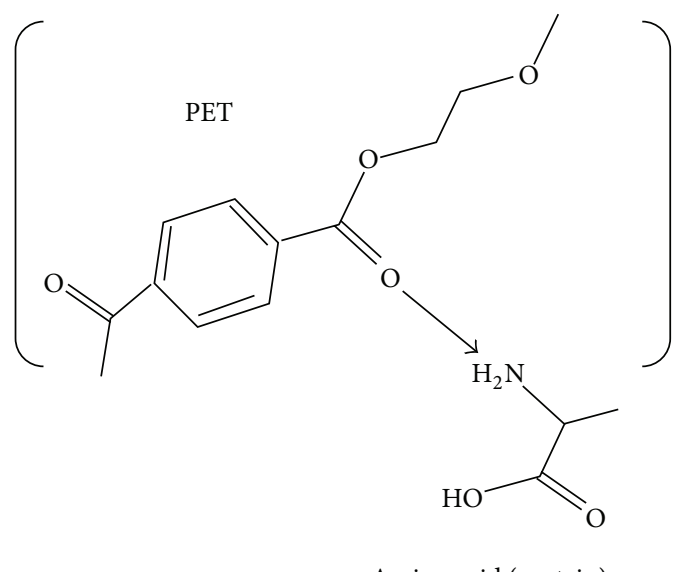

Amino acid (protein)

FIgURE 3: PET-protein chemical interaction.

The morphological characterization of salmon tissue adhered to the polymer showed not only the adhesion of physical portions of raw material related to the surface roughness and flaws of the coating but stronger long-lasting bonds. 


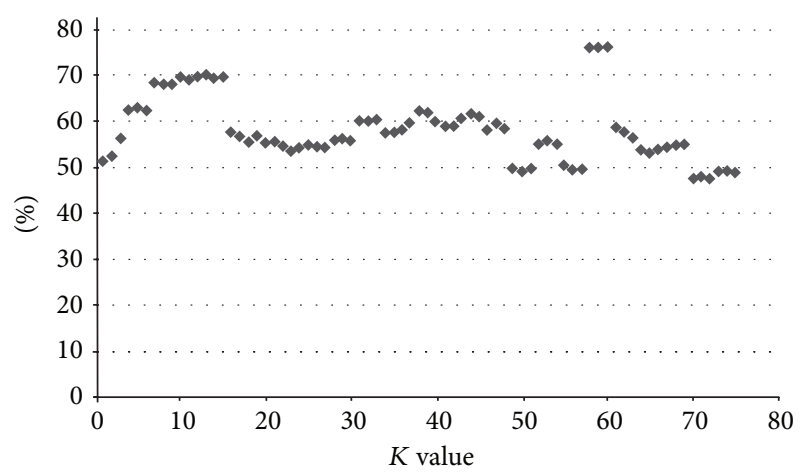

FIgURE 4: $K$ value, freshness quality index of canned salmon.

\subsection{Evaluation of Chemical and Structural Changes of the} PET Coating by Vibrational Spectroscopy: ATR, FT-IR, and Raman. In this work we intended to identify any changes occurring on the polymer in contact with the salmon tissues and also explore the possibility of contamination. Sample M1 is from salmon tissue adhered to the container wall and sample M2 is from muscle treated with urea. Figure 5 shows the spectroscopy results of samples M1 and M2; the last digit refers to their position on the images.

3.2.1. FT-IR. FT-IR spectra were measured on different points of the sample with a PerkinElmer Spectrum 100 spectrometer equipped with a universal ATR accessory. These points were very similar to those employed in the Raman spectroscopy analyses in order to determine differences and similarities between the results of both methods. The nomenclature of the spectra followed that established in Figure 5 and, in general, spectra were taken from areas without remains of salmon, areas with stains arising from the contact with salmon, and areas with small portions of salmon adhered to the surface. In the case of sample M2, no appreciable areas of the latter type were found.

Figure 6 shows some of the differences observed between the spectra of M1, corresponding to muscle naturally adhered to the can wall, and M2 belonging to the urea-treated container to detach the salmon flesh and where no appreciable remains of salmon can be seen.

These differences were clearly associated with the presence of urea in the sample M2 with residues easily noticeable: bands $v(\mathrm{NH})$ at 3220 and $3360 \mathrm{~cm}^{-1}$, the $v(\mathrm{C}=\mathrm{O})$ band at $1676 \mathrm{~cm}^{-1}$, and deformation bands $\delta(\mathrm{NH} 2)$ at 1630 and $1595 \mathrm{~cm}^{-1}$, respectively. That is, the protective polymer allowed for the adhesion of salmon on certain given areas depending on the heterogeneity of the surface, defects, and pores. The urea solution treatment was not able to detach all of the material adhered to the polymer surface and small residues remained attached as indicated by the FT-IR analyses.

Even though the spectra are fairly homogeneous within each sample, the spectroscopy analyses are capable of characterizing them for quality control purposes of the canning processes. Thus, Figure 7 shows the spectra taken at points where salmon muscle adhesion was clearly visible (points 8

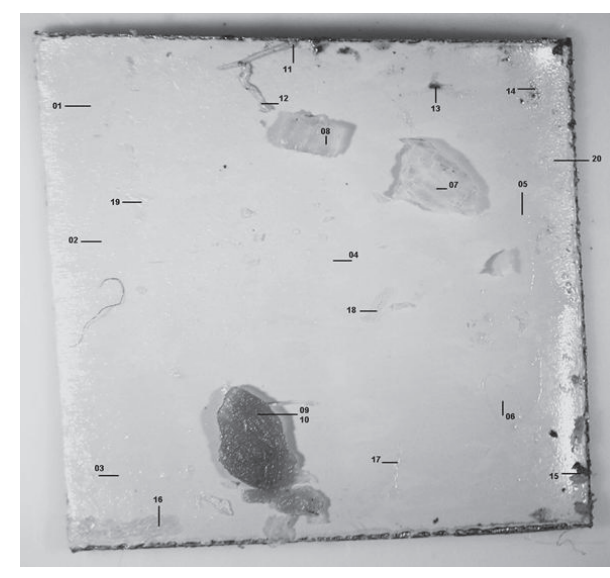

(a)

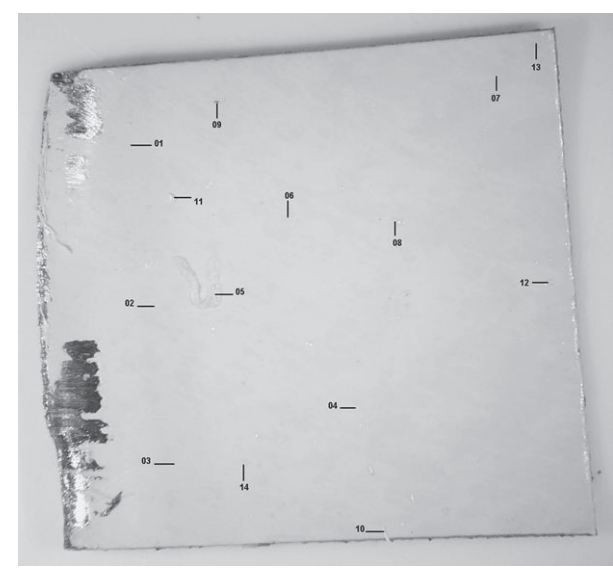

(b)

FIgUre 5: (a) Sample M1 of PET-coated ECCS plate showing zones of salmon muscle adhesion; numbers indicate points of spectral analyses. (b) Layout of points for spectral analyses in urea-treated sample M2.

and 9 in Figure 5) and hardly noticeable (point 6 in Figure 5) in sample M1, demonstrating the sensitivity of the spectral analyses performed. The spectrum of PET in points 8 and 9 remains largely concealed; however, the $\mathrm{C}=\mathrm{O}$ band of the protein at $1743 \mathrm{~cm}^{-1}$ can be easily seen. In point 6 , this band appears as a shoulder of the $\mathrm{C}=\mathrm{O}$ band of PET.

3.2.2. Micro-Raman Spectroscopy. Figure 8 shows the microRaman spectral measurements made in nondegraded areas of samples M1 and M2, respectively, whose references to points in Figure 5 can be seen in the upper right side. In some spots, such as point 5 in sample M2 (M2-P5), the concentration of urea was very high as indicated by the most intense band observed at $1013 \mathrm{~cm}^{-1}$. Also the bands at 136,548 , and $1541 \mathrm{~cm}^{-1}$ were also detected. In other spots the intense band of urea was observed as a shoulder of the $1003 \mathrm{~cm}^{-1}$ band of PET. These results showed that the distribution of the residual urea on the PET surface was not homogeneous. No bands from urea were detected in sample M1 and, in general, the spectra observed were quite homogeneous and represented the structure of PET. 


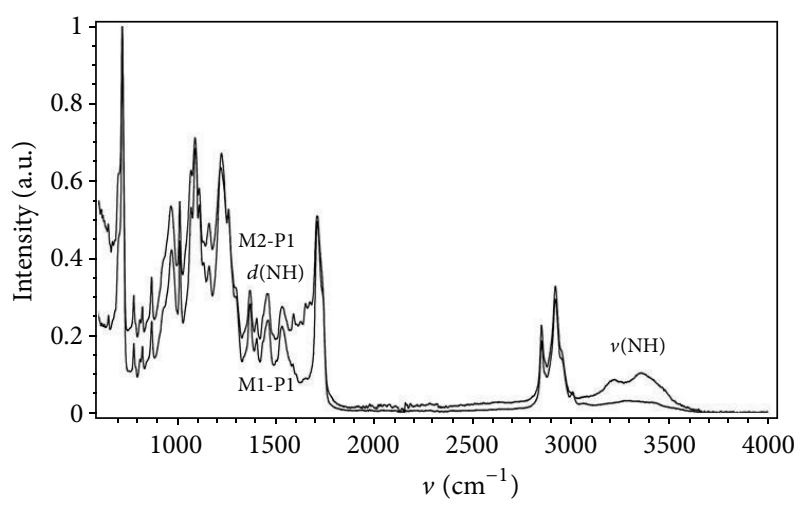

FIgURE 6: ATR spectra from samples M1 (bottom) and M2 (top) measured in areas of reduced contamination (point 1 in Figure 5).

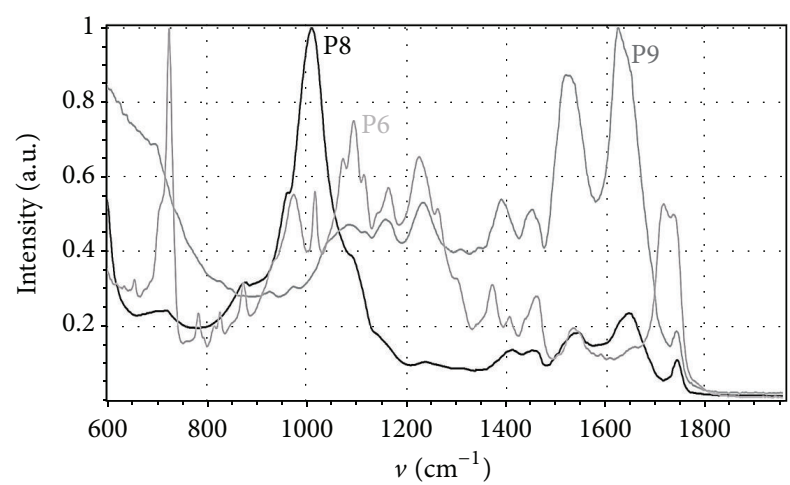

FIgURE 7: ATR spectra taken on sample M1 at positions where remains of adhered salmon were observed. Points 6, 8, and 9 from Figure 5.

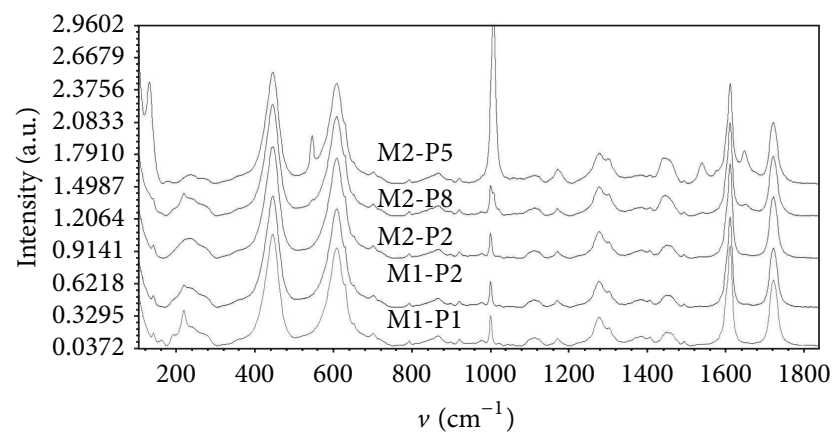

FIGURE 8: Raman spectra from nondegraded areas of samples M1 and M2. The spectrum for point 5 in sample M2 is dominated by urea bands.

Figure 9 shows the micro-Raman spectra from areas degraded by salmon adhesion in sample M1 and compares them with the spectrum taken at a nondegraded spot (point P1). Even though the spectra are similar, those bands corresponding to adhered salmon muscle can be easily distinguished. These bands can be seen at $960 \mathrm{~cm}^{-1}, 1260 \mathrm{~cm}^{-1}$, $1300 \mathrm{~cm}^{-1}, 1440 \mathrm{~cm}^{-1}$, and $1657 \mathrm{~cm}^{-1}$. The spectral plot shows the correlation between bands and adhered muscle and can

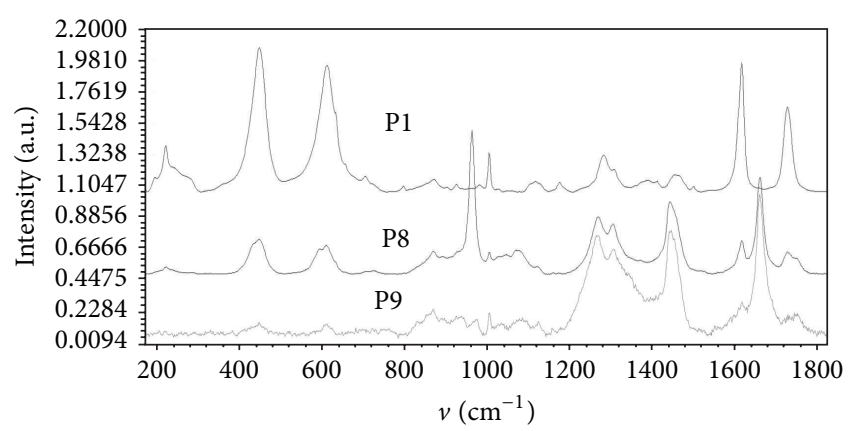

FIGURE 9: Micro-Raman spectra from areas of salmon adhesion in sample M1; points 01, 08, and 09 in Figure 5.

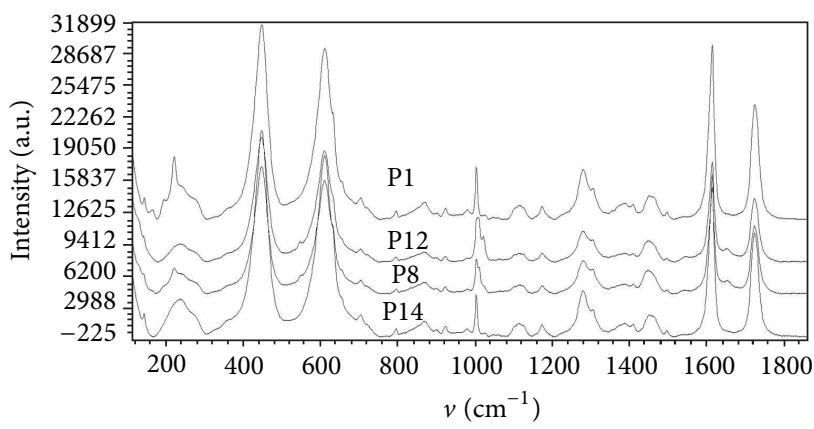

Figure 10: Micro-Raman spectra at grey areas of sample M2 where salmon adhesion was observed. Spectral plots P1, P8, P12, and P14 correspond to points $01,08,12$, and 14 in Figure 5.

therefore determine if the polymer surface has undergone any damage. The above values indicated no significant effects on the polymer surface structure; however, it was possible to characterize the different areas of the samples. Nevertheless, band $960 \mathrm{~cm}^{-1}$ can be attributed to the symmetrical vibration of the phosphate group, possibly resulting from the contamination of salmon during the canning process; therefore, Raman spectroscopy becomes a useful tool by showing the presence of elements potentially threatening the human health or affecting the PET surface and the recycling capabilities. Work is in progress to identify the spectral characteristics of different parts of salmon.

Figure 10 shows a similar analysis that was performed on sample M2, comparing grey areas where visual remains of salmon were observed with clear areas (P1). No evidence of Raman bands was observed as a consequence of the urea treatment. The urea band at $1013 \mathrm{~cm}^{-1}$ was observed as a shoulder of the $1003 \mathrm{~cm}^{-1}$ band of PET, as previously mentioned.

The most outstanding of these results was the presence of urea in almost all the spots of sample M2, with the characteristic band $v(\mathrm{CN})$ at $1003 \mathrm{~cm}^{-1}$ and variable intensity. Even though salmon residues were persistent after the urea treatment, no bands were seen for salmon muscle; however, the urea employed to remove the salmon residues could be identified on the PET surface. 
The degradation of PET coatings by salmon muscle is time dependent and it can be further monitored using local techniques with higher spatial resolution. In this sense, electron probe microanalyses (EPMA) can be used to collect qualitative and quantitative elemental information to establish the composition of small areas on specimens at a nanoscale level. In addition, Kelvin probe force microscopy (KPFM) can be a useful tool to study the composition and electronic state at the surface of materials.

\section{Conclusions}

This study evaluated the adhesion of salmon to PET polymer coatings employed in canning processes in order to understand this physicochemical phenomenon and hence minimize adhesion for the benefit of consumers.

Thermal treatment of containers is directly related to the loss of freshness, understood as the lack of ability to meet sensory and chemical requirements for a long shelf life, as indicated by $\mathrm{pH}$ and $K$ index values. Fish spoilage facilitates adhesion of salmon tissue to the container wall; proteins are responsible for the formation of bonds between the PET coating and salmon muscle, and the application of urea makes evident the presence of noncovalent bonds due to the easy removal of the remaining tissue.

The morphology characterization of the PET polymer in areas of salmon adhesion by scanning electron microscopy (SEM) showed a homogeneous contact surface; however, surface pores, roughness, or polymer microfolds favored adhesion of muscle proteins to the container.

Spectroscopy analyses showed the presence of PET and rutile, as well as salmon tissue adhered to the polymer surface. Areas with salmon adhesion or surface degraded showed small microstructural changes; the PET polymer with small traces of urea did not show the same crystallinity, as indicated by the low Raman frequencies. This would prove that the urea solution activity causes changes on the polymer, compromising its functionality in degraded areas.

Finally, the vibrational techniques allowed the understanding of the adhesion mechanisms of salmon to polymercoated can walls and discerning the changes undergone after the urea treatments employed to minimize the amount of salmon adhering in salmon canning processes.

\section{Conflict of Interests}

The authors declare that there is no conflict of interests regarding the publication of this paper.

\section{Acknowledgments}

The authors gratefully acknowledge Fondecyt Program of Conicyt Chile for the financial support through Grant no. 1130634 and the special contribution of University Austral of Chile.

\section{References}

[1] Z. Jiang, H. Neetoo, and H. Chen, "Control of Listeria monocytogenes on cold-smoked salmon using chitosan-based antimicrobial coatings and films," Journal of Food Science, vol. 76, no. 1, pp. 22-26, 2011.

[2] F. Lu, D. Liu, X. Ye, Y. Wei, and F. Liu, "Alginate-calcium coating incorporating nisin and EDTA maintains the quality of fresh northern snakehead (Channa argus) fillets stored at $4^{\circ} \mathrm{C}$," Journal of the Science of Food and Agriculture, vol. 89, no. 5, pp. 848-854, 2009.

[3] M. Mariscal-Arcas, A. Rivas, A. Granada, C. Monteagudo, M. A. Murcia, and F. Olea-Serrano, "Dietary exposure assessment of pregnant women to bisphenol-A from cans and microwave containers in Southern Spain," Food and Chemical Toxicology, vol. 47, no. 2, pp. 506-510, 2009.

[4] U. Rafique, S. Iqbal, S. Faiz, and A. Hashmi, "Analysis of variation in concentration of essential and non essential elements in canned and fresh food," Journal of Food Processing and Preservation, vol. 33, no. 2, pp. 186-203, 2009.

[5] A. Rodríguez, N. Carriles, J. M. Gallardo, and S. P. Aubourg, "Chemical changes during farmed coho salmon (Oncorhynchus kisutch) canning: effect of a preliminary chilled storage," Food Chemistry, vol. 112, no. 2, pp. 362-368, 2009.

[6] M. Mastromatteo, A. Danza, A. Conte, G. Muratore, and M. A. del Nobile, "Shelf life of ready to use peeled shrimps as affected by thymol essential oil and modified atmosphere packaging," International Journal of Food Microbiology, vol. 144, no. 2, pp. 250-256, 2010

[7] Y. Byun, H. J. Bae, K. Cooksey, and S. Whiteside, "Comparison of the quality and storage stability of salmon packaged in various retort pouches," LWT-Food Science and Technology, vol. 43, no. 3, pp. 551-555, 2010.

[8] G. Choubert, F. Brisbarre, D. Parfouru, and M. Baccaunaud, "Argon modified atmosphere packaging for fillets of rainbow trout (Oncorhynchus mykiss) fed astaxanthin or canthaxanthin," Journal of Aquatic Food Product Technology, vol. 17, no. 2, pp. 117-136, 2008.

[9] G. C. Fletcher, V. K. Corrigan, G. Summers, M. J. Leonard, A. R. Jerrett, and S. E. Black, "Spoilage of rested harvested king Salmon (Oncorhynchus tshawytscha)," Journal of Food Science, vol. 68, no. 9, pp. 2810-2816, 2003.

[10] T. Geens, L. Goeyens, and A. Covaci, "Are potential sources for human exposure to bisphenol-a overlooked?" International Journal of Hygiene and Environmental Health, vol. 214, no. 5, pp. 339-347, 2011.

[11] E. Zumelzu, F. Rull, C. Ortega, and C. Cabezas, "Effect of temperature on polyethylene teraphthalate coated ECCS plates in acetic-acetate medium," Journal of Applied Polymer Science, vol. 113, no. 3, pp. 1853-1859, 2009.

[12] E. Zumelzu, F. Rull, and C. Ortega, "Titanium dioxide performance in polyethylene teraphthalate protective coatings on electrolytic chromium coated steels," Surface Engineering, vol. 25, no. 2, pp. 111-115, 2009.

[13] C. Schick, A. Wurm, and A. Mohammed, "Formation and disappearance of the rigid amorphous fraction in semicrystalline polymers revealed from frequency dependent heat capacity," Thermochimica Acta, vol. 396, no. 1-2, pp. 119-132, 2003.

[14] E. Zumelzu, C. Cabezas, and R. Alvarado, "Evaluation of the degradation of traditional and ECCS canning tinplates in acetic-acetate medium," Science and Engineering of Composite Materials, vol. 13, no. 1, pp. 13-20, 2006. 
[15] X. D. Chen, L. Zhang, and D. Li, “The combined effects of heat transfer coefficient and thermal diffusivity on heating rates of solid materials-a simple analysis," International Journal of Food Engineering, vol. 4, no. 5, article 2, 2008.

[16] X. D. Chen, "Simultaneous heat and mass transfer," in Handbook of Food and Bioprocess Modeling Techniques, S. S. Sablani, A. K. Datta, M. S. Rahman, and A. S. Mujumdar, Eds., Chapter 6, CRC Press, 2007.

[17] O. Fennema, Quimic a de los Alimentos, Acribia S.A., Zaragoza, Spain, 2000.

[18] S. Bistac, M. F. Vallat, and J. Schultz, "Durability of steel/ polymer adhesion in an aqueous environment," International Journal of Adhesion and Adhesives, vol. 18, no. 5, pp. 365-369, 1998.

[19] H. D. Belitz and W. Grosch, Food Chemistry, Springer, Berlin, Germany, 2nd edition, 1999.

[20] G. Curtzwiler, K. Vorst, J. E. Danes, R. Auras, and J. Singh, "Effect of recycled poly(ethylene terephthalate) content on properties of extruded poly(ethylene terephthalate) sheets," Journal of Plastic Film and Sheeting, vol. 27, no. 1-2, pp. 65-86, 2011.

[21] A. L. Galo and M. F. Colombo, "Singular value decomposition and ligand binding analysis," Journal of Spectroscopy, vol. 2013, Article ID 372596, 7 pages, 2013.

[22] R. A. Sayed, W. S. Hassan, M. Y. El-Mammli, and A. Shalaby, "New spectrophotometric and conductometric methods for macrolide antibiotics determination in pure and pharmaceutical dosage forms using rose Bengal," Journal of Spectroscopy, vol. 2013, Article ID 214270, 13 pages, 2013.

[23] E. Zumelzu, I. Asomavich, F. Rull, and C. Cabezas, "Evaluation of $\mathrm{NaCl}$ effect on vibration-delaminated metal-polymer composites by improved micro-raman methodology," Journal of Spectroscopy, vol. 2013, Article ID 742681, 6 pages, 2013.

[24] N. N. Brandt, A. Y. Chikishev, A. A. Mankova, M. M. Nazarov, I. K. Sakodynskaya, and A. P. Shkurinov, "THz and IR spectroscopy of molecular systems that simulate function-related structural changes of proteins," Journal of Spectroscopy, vol. 27, no. 5-6, pp. 429-432, 2012. 

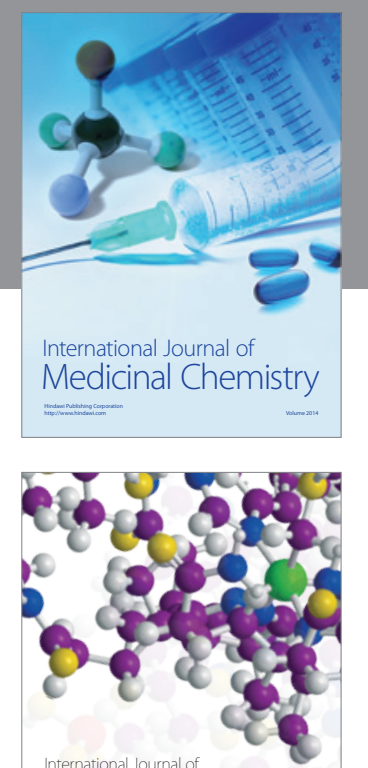

\section{Carbohydrate} Chemistry

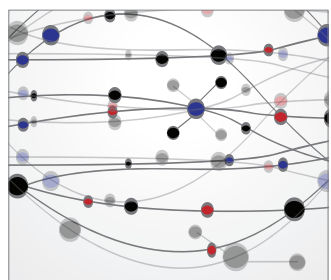

The Scientific World Journal
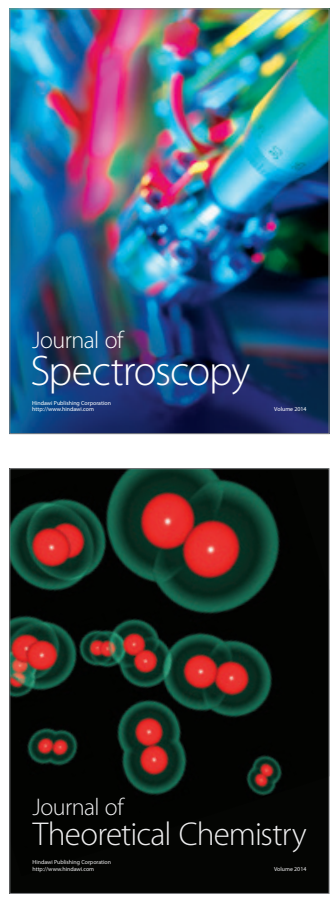
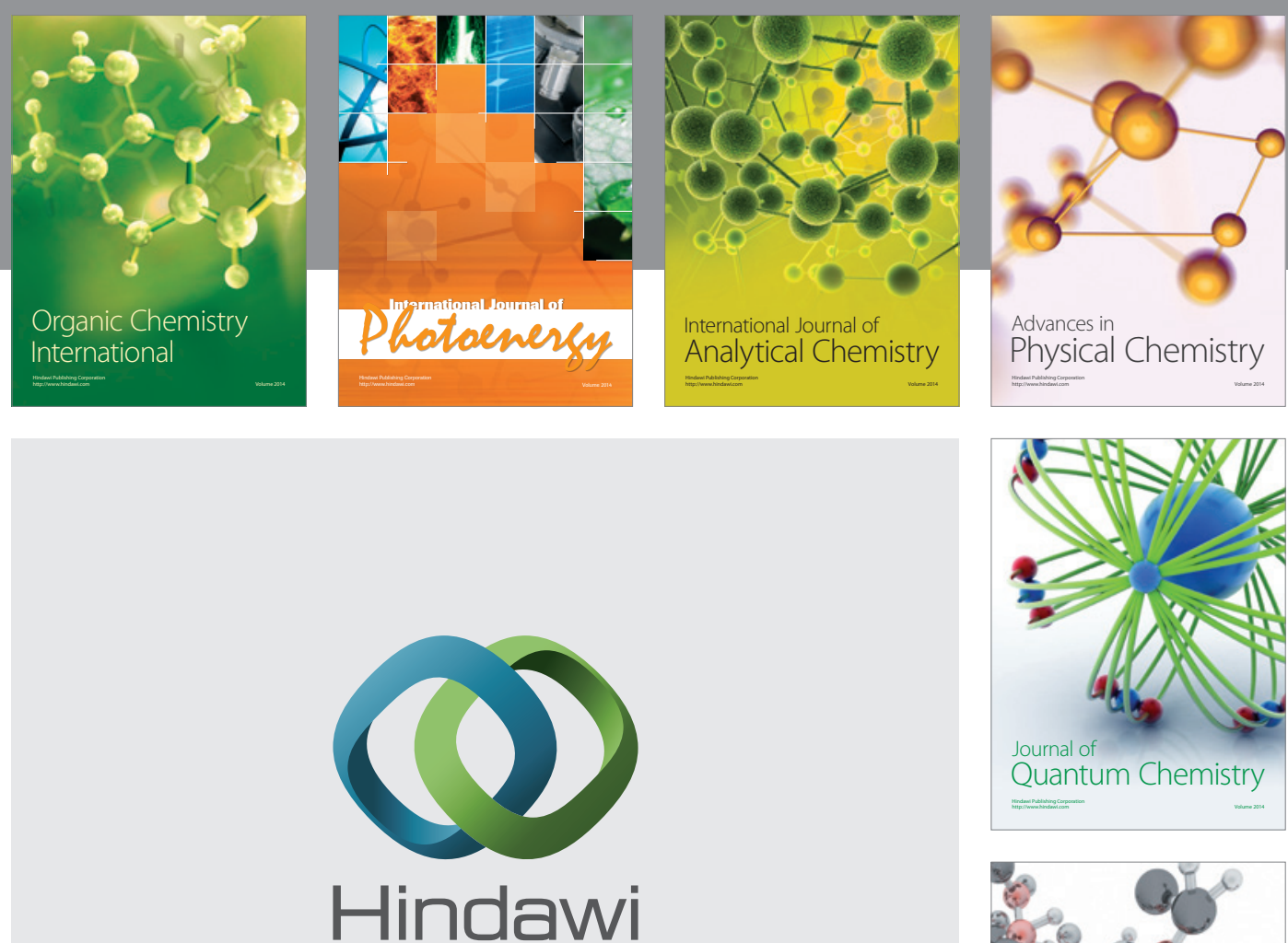

Submit your manuscripts at

http://www.hindawi.com

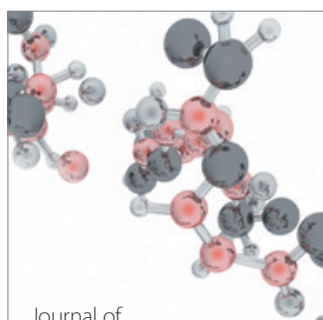

Analytical Methods

in Chemistry

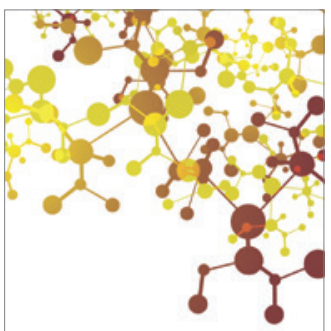

Journal of

Applied Chemistry

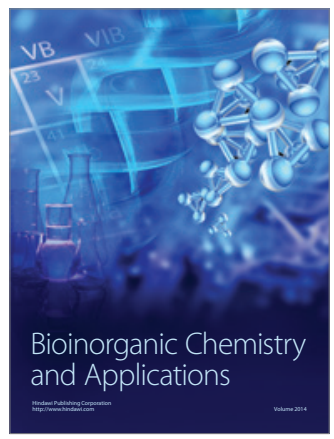

Inorganic Chemistry
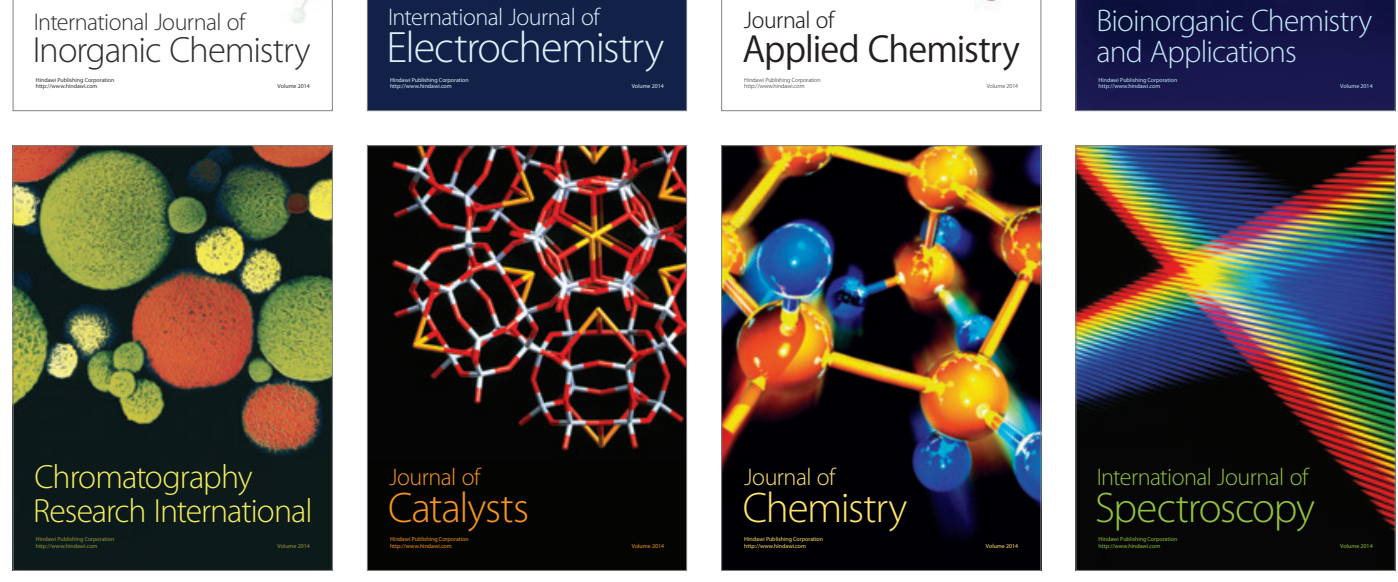